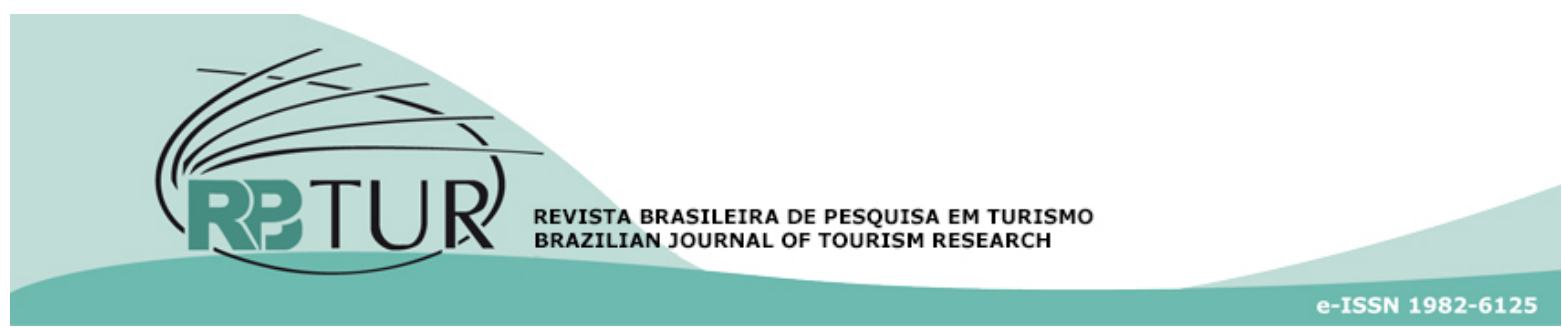

Artigos

\title{
Análise e perspectivas do turismo no Brasil
}

\author{
Analysis and prospects of tourism in Brazil
}

Análisis y perspectivas del turismo en Brasil

\author{
Wilson Abrahão Rabahy ${ }^{1}$ \\ 1Universidade de São Paulo (USP), São Paulo, Brasil.
}

\author{
Palavras-chave: \\ Economia do turismo; \\ Turismo no Brasil; \\ Turismo receptivo internacional; \\ Turismo doméstico; \\ Demanda turística; \\ Balança de pagamentos do \\ turismo.
}

Keywords:

Tourism economics; Tourism in Brazil; Inbound tourism; Domestic tourism; Tourist demand;

Tourism balance of payments.

Palavras clave:

Economía del turismo; Turismo en Brasil; Turismo receptivo internacional; Turismo interno;

Demanda turística;

Balanza de pagos turísticos.

\section{Resumo}

Este texto traz uma síntese da atividade turística no Brasil, apresentando e analisando estatísticas sob a perspectiva econômica. Para tanto, são reunidos dados das principais fontes oficiais disponíveis, bem como informações sobre o turismo produzidas pela Fundação Instituto de Pesquisas Econômicas (FIPE). Inicialmente são apresentadas análises sobre o mercado mundial de turismo. Em seguida, é discutida a realidade do turismo internacional receptivo do Brasil, incluindo relações entre renda, preços, taxa de câmbio e turismo. Três análises sobre o turismo no Brasil são destacadas: a importância do turismo doméstico, as oportunidades existentes no turismo receptivo internacional e os impactos do turismo na distribuição regional de renda. Por fim, o texto apresenta algumas recomendações para o turismo no Brasil.

\section{Abstract}

This paper provides a summary of tourism activity in Brazil, presenting and analyzing statistics from an economic perspective. To this end, data are collected from the main official sources available, as well as from tourism surveys conducted by the Institute of Economic Research Foundation (FIPE). The first section presents an analysis of the global tourism market. Next, the paper discusses Brazil\&\#39;s inbound tourism, including the effects of income, prices, and exchange rate. Three analyzes of tourism in Brazil are highlighted: the importance of domestic tourism, the opportunities of inbound tourism, and the impacts of tourism on regional income distribution. Finally, the paper presentes some recommendations for tourism in Brazil.

\section{Resumen}

Este artículo resume la actividad turística en Brasil, presentando y analizando estadísticas desde una perspectiva económica. Con este fin, se recopilan datos de las principales fuentes oficiales disponibles, así como información sobre turismo producida por el Instituto Fundação de Pesquisas Econômicas (FIPE). Inicialmente, se presentan análisis sobre el mercado turístico mundial. A continuación, se discute la realidad del turismo internacional receptivo de Brasil, incluidas las relaciones entre ingresos, precios, tipo de cambio y turismo. Se destacan tres análisis sobre el turismo en Brasil: la importancia del turismo interno, las oportunidades existentes en el turismo receptivo internacional y los impactos del turismo en la distribución regional del ingreso. Finalmente, el texto presenta algunas recomendaciones para el turismo en Brasil. 


\section{CONSIDERAÇÕES INICIAIS}

O turismo constitui-se em uma importante atividade econômica, capaz de gerar renda, emprego, divisas e redistribuir a renda regional (Haddad, Porsee, \& Rabahy, 2013). As atividades turísticas, assim como demais atividades que envolvem o consumo de bens privados, preponderam com a origem em regiões mais ricas, mas, em termos relativos, a renda gerada pelo turismo pode ser mais relevante naquelas menos desenvolvidas e que não apresentam a mesma diversidade de atividades produtivas. Assim, a diminuição de desigualdades regionais de renda é um dos significativos benefícios do turismo.

De outra parte, por se constituir preponderantemente numa atividade do setor de serviços, que utiliza mãode-obra de forma mais intensiva, o potencial gerador de empregos do turismo também é muito relevante. Segundo o IBGE (2009), as atividades características do turismo brasileiro respondem por cerca de $6 \%$ do emprego total do país, sendo mais de $50 \%$ devido ao setor de alimentação, que, como se sabe, atende também o consumo de residentes não turistas. Com o intuito de quantificar apenas as ocupações geradas diretamente pela atividade do turismo, uma estimativa preliminar foi desenvolvida pela Fundação Instituto de Pesquisas Econômicas (FIPE) para o Instituto Brasileiro do Turismo (Embratur) em 2002, e seguiu os moldes das recomendações da Conta Satélite do Turismo (CST) da Organização Mundial do Turismo (OMT ou UNWTO), chegando ao valor de $2,3 \%$ do total de ocupações no país, e quando considerados os efeitos indiretos, totaliza 3,3\% da população economicamente ativa (Kadota \& Rabahy, 2003).

No que tange à geração de divisas, o turismo também é considerado uma importante atividade, particularmente para os países onde o turismo receptivo internacional é expressivo. Não é o caso ainda do Brasil, em que a relação de receitas do turismo interno é cerca de nove vezes superior à do receptivo internacional, sendo que o país recebe apenas $0,47 \%$ do total de turistas internacionais mundiais e $0,35 \%$ de seus gastos (EMBRATUR, 2002; UNWTO, 2019; Ministério do Turismo, 2019; Banco Central do Brasil, 2019).

Tal situação é decorrente, de um lado, da força do mercado interno brasileiro, e, de outro, de sua localização, relativamente distante dos principais emissores mundiais, a Europa, Ásia e América do Norte, que respondem por mais de $80 \%$ do emissivo mundial e estão a mais de 9 horas de distância do Brasil, mesmo com o uso do modal aéreo. Apenas uma pequena margem de turistas destas regiões se destina ao Brasil (Rabahy, 2003; UNWTO, 2018; UNWTO, 2019).

De outro lado, os gastos dos brasileiros no exterior apresentam íntima relação com a renda e, em especial, com as flutuações de câmbio. A moeda nacional valorizada estimula a saída de brasileiros e representa restrições de custos para a entrada de estrangeiros, particularmente dos países situados em localidades fronteiriças, os quais, assim como os brasileiros, além do câmbio, respondem também às respectivas variações da renda (Rabahy, Silva, \& Vassallo, 2007).

O Brasil apresenta condições particulares de sustentação do crescimento de seu turismo a partir do fortalecimento do mercado interno. Ainda que não se justifique como foco primário para o desenvolvimento da atividade no país, o turismo internacional acaba se beneficiando da estrutura desenvolvida e sustentada pelo turismo doméstico. Os mercados interno e o externo não se excluem, mas, pelo contrário, podem resultar em benéficas interações em favor da melhoria das condições do turismo em geral. Para tanto, devem ser estabelecidas estratégias para cada um dos tipos de emissivo (doméstico e internacional) e para cada uma das regiões receptivas do país, em que preponderam diferentes tipos de atrativos, capazes de atender diferentes tipos de segmentos de consumo. 
Dado o tamanho de seu território e a disponibilidade de uma ampla diversidade de atrativos e de belezas naturais, é consequência natural a enorme potencialidade que o Brasil apresenta para atender uma maior parcela do mercado mundial do turismo.

\section{MERCADO MUNDIAL DE TURISMO}

O número de viagens internacionais realizadas em todo mundo vem crescendo consideravelmente nos últimos anos: taxas de crescimento de 4,01\% a.a., contra 3,65\% a.a. do PIB mundial em valores constantes, no período 2000 a 2017. No entanto, ao longo do tempo, apresenta flutuações associadas aos ciclos da economia mundial (Gráfico 1). Confrontando-se as taxas anuais do número de chegadas do turismo no mundo e do PIB mundial (Gráfico 1), pode-se observar alta correlação entre os movimentos das duas variáveis, corroborando com a hipótese do turismo ser considerado uma atividade elástica com relação à renda.

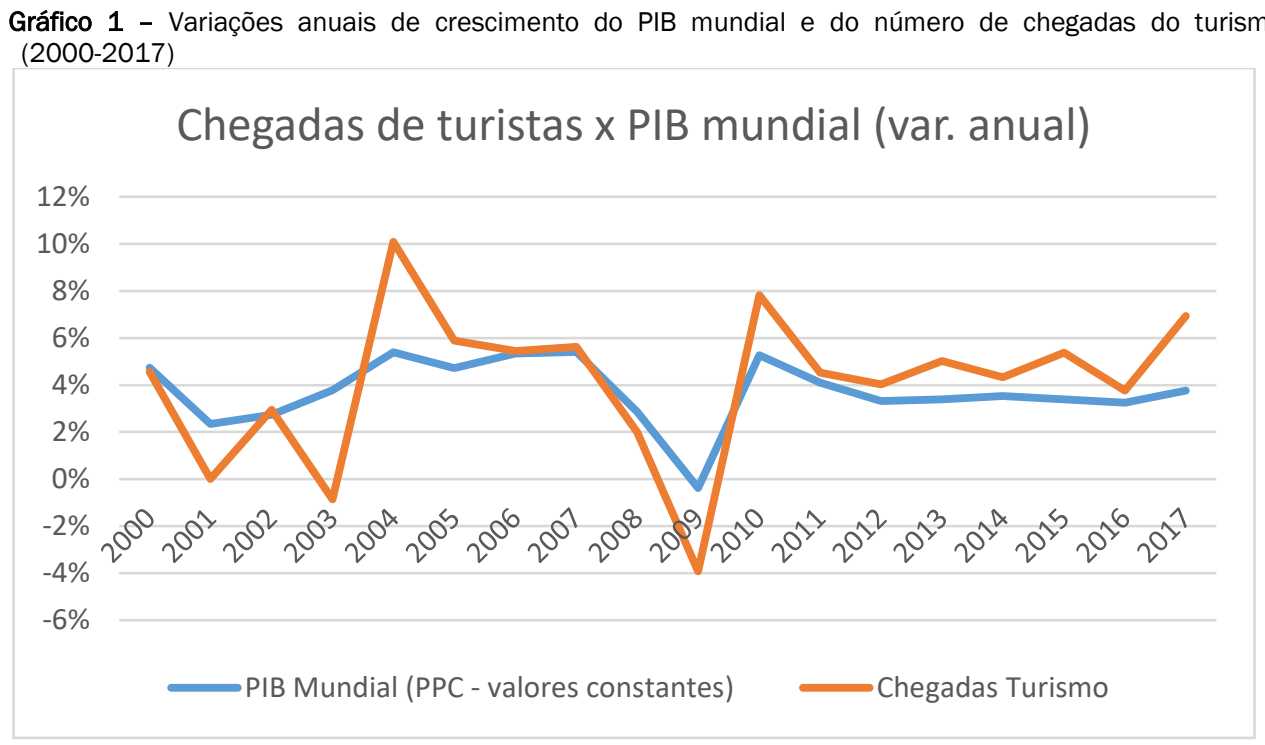

Fonte: World Economic Outlook Database (FMI) e UNWTO Highlights

Desenvolvimentos tecnológicos, relacionados particularmente aos setores de transporte e de comunicação; avanços no processo de globalização; aumento da renda real; aumento do tempo livre para o lazer; e as consequentes mudanças no comportamento de consumo dos indivíduos, propiciaram maiores oportunidades para o turismo, antes uma atividade reservada a reduzidos segmentos da população detentores de altos níveis de renda.

No entanto, esse significativo crescimento do turismo, que vem ocorrendo desde o final do século passado, não se propaga de modo uniforme entre todos os países. De fato, analisando-se em grupos de regiões, representados pelos continentes, observa-se uma forte concentração das atividades turísticas em alguns deles, tanto do emissivo, quanto do receptivo.

Como se observa no Gráfico 2, tem-se uma significativa concentração das chegadas em algumas das mais desenvolvidas regiões do mundo. Nada menos do que 51\% do total mundial (2018) se destina à Europa, acrescentando-se Ásia e Pacífico (+24\%) e América do Norte (+10\%), tem-se 85\% do total mundial. Deve-se salientar, no entanto, que, ao longo do tempo, vem sendo observada uma tendência de desconcentração do receptivo (em 1990 a Europa respondia por 60,2\%; perda de quase 10 pontos percentuais).

Uma das razões é o aumento e melhor distribuição da renda mundial, ao lado da importância do processo de globalização e a ascensão econômica de novas potências, os chamados países emergentes, em particular da China. Ásia/Pacífico passa de 55,9 milhões (12,9\%) para 345,1 milhões de turistas (24,6\%), um adicional de quase 290 milhões de turistas entre os anos de 1990 e 2018 (+ 11,7 pontos percentuais).

Deve-se ressaltar que, pelas restrições de tempo e renda, além da insegurança com o desconhecido, as mais expressivas parcelas das viagens ocorrem em destinos mais próximos do local de origem, caracterizando o 
turismo como uma atividade em que preponderam as viagens intraregionais. Quase $80 \%$ do turismo mundial é realizado dentro da mesma região (Rabahy, 2003).

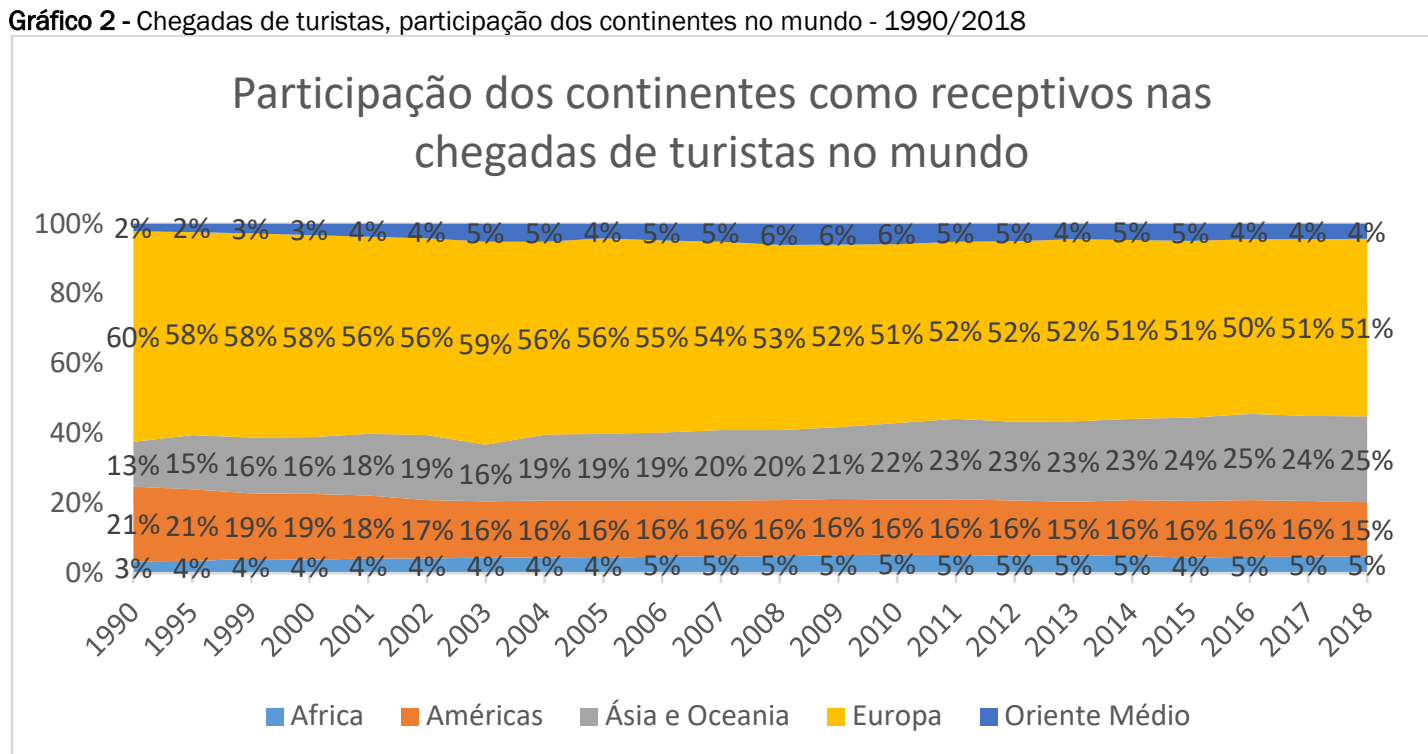

Fonte: UNWTO Highlights (2001 a 2019)

Situação similar verifica-se em nível dos países. Em apenas 10 deles, os mais desenvolvidos, concentra-se $47,6 \%$ das receitas do turismo mundial (Tabela 1 ).

Por outro lado, observa-se também expressiva concentração do emissivo mundial em regiões e países mais desenvolvidos. 0 turismo caracteriza-se por ser uma atividade que envolve bens e serviços não essenciais e, como tal, apresenta alta elasticidade-renda. Dessa forma, no que se refere aos gastos, verifica-se assimetria com concentração de emissão de gastos nos países mais populosos e ricos (Tabela 1). Observase que em apenas 10 países concentra-se $55,7 \%$ dos gastos totais com o turismo internacional. Dentre estes, sete países são comuns nos dois lados, como emissores e também receptores no turismo internacional: China, Estados Unidos, Alemanha, Reino Unido, França, Austrália e Itália, concentrando 48,8\% dos gastos e 35,3\% das receitas. Esta constatação reforça a expectativa da predominância dos fluxos entre regiões desenvolvidas.

\begin{tabular}{|c|c|c|c|c|c|}
\hline \multirow{2}{*}{$\begin{array}{l}\text { Principais Países } \\
\text { Emissores }\end{array}$} & \multicolumn{2}{|c|}{ Gastos (2018) } & \multirow{2}{*}{\begin{tabular}{|l|} 
Principais Países \\
Receptores
\end{tabular}} & \multicolumn{2}{|c|}{ Receitas (2018) } \\
\hline & (US\$ bilhões) & (\%) & & (US\$ bilhões) & (\%) \\
\hline China(*) & 277,3 & 19,2 & Estados Unidos(*) & 214,5 & 14,8 \\
\hline Estados Unidos(*) & 144,2 & 10,0 & Espanha & 73,8 & 5,1 \\
\hline Alemanha(*) & 94,2 & 6,5 & França(*) & 67,4 & 4,7 \\
\hline Reino Unido(*) & 75,8 & 5,2 & Tailândia & 63 & 4,4 \\
\hline França(*) & 47,9 & 3,3 & Reino Unido ${ }^{*}$ ) & 51,9 & 3,6 \\
\hline Austrália(*) & 36,8 & 2,5 & Itália(*) & 49,3 & 3,4 \\
\hline Rússia & 34,5 & 2,4 & Austrália(*) & 45 & 3,1 \\
\hline Canadá & 33,3 & 2,3 & Alemanha(*) & 43 & 3,0 \\
\hline Coréia & 32 & 2,2 & Japão & 41,1 & 2,8 \\
\hline Itália(*) & 30,1 & 2,1 & China $(*)$ & 40,4 & 2,8 \\
\hline Sub-Total & 806,1 & 55,7 & Sub-Total & 689,4 & 47,6 \\
\hline Demais Países & 641,9 & 44,3 & Demais Países & 758,6 & 52,4 \\
\hline TOTAL & $1.448,0$ & 100,0 & TOTAL & $1.448,0$ & 100,0 \\
\hline
\end{tabular}

(*) Países que aparecem entre os 10 principais emissores e receptores

Fonte: UNWTO Barometer - 2019 


\section{TURISMO INTERNACIONAL NO BRASIL}

\subsection{Principais Países Emissores ao Brasil}

Corroborando esta constatação, a principal região emissiva ao Brasil, em número de turistas, é a América do Sul, com $61,2 \%$ do total, seguida da Europa $(22,1 \%)$ e da América do Norte (10,4\%), acumulando 93,7\% (Ministério do Turismo, 2019). No período 2000 a 2018, a contribuição da América do Sul, cresceu 4 pontos percentuais, embora, em anos de crise tenha perdido mais de 20 pontos (2000 a 2006). Os ganhos da América do Sul ocorreram em detrimento da Europa (- 2,5 pontos) e América do Norte (- 3,6 pontos) - Gráfico 3.

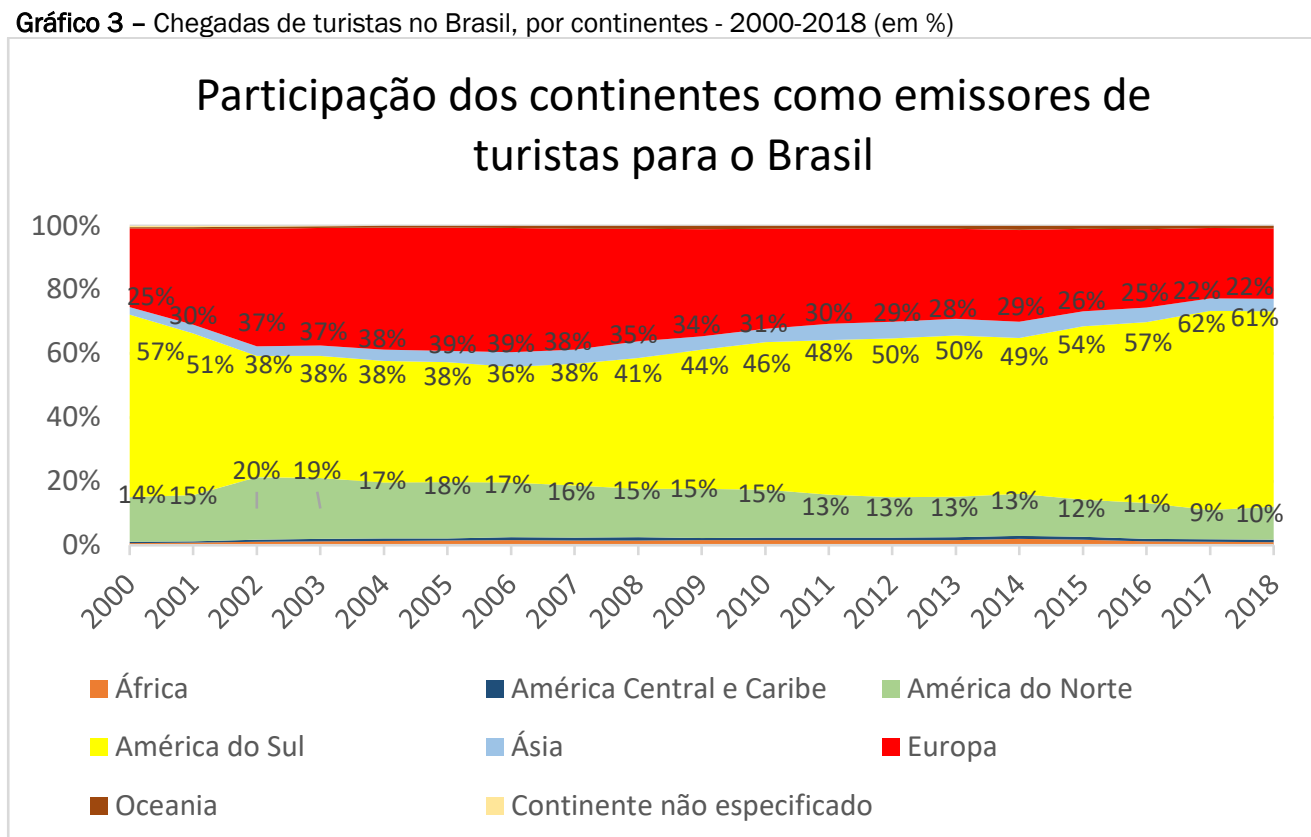

Fonte: Ministério do Turismo e Embratur - Anuários Estatísticos - 2001 a 2019.

Sabe-se, por outro lado, que os turistas provenientes de outros continentes possuem gastos per capita superiores à média das visitas, que incluem os países vizinhos. Isto ocorre também no Brasil, quanto mais distante a origem e maior o nível de renda dos emissores, maior o gasto per capita - Gráfico 4. Isto porque, o tipo de turistas que viaja longas distancias representa a parcela menos massificada, que em geral dispõe de mais tempo de permanência e maior nível de renda.

Gráfico 4 - Gastos per capita no Brasil, por país de residência do turista e linha de média geral do receptivo - 2018 (US\$)

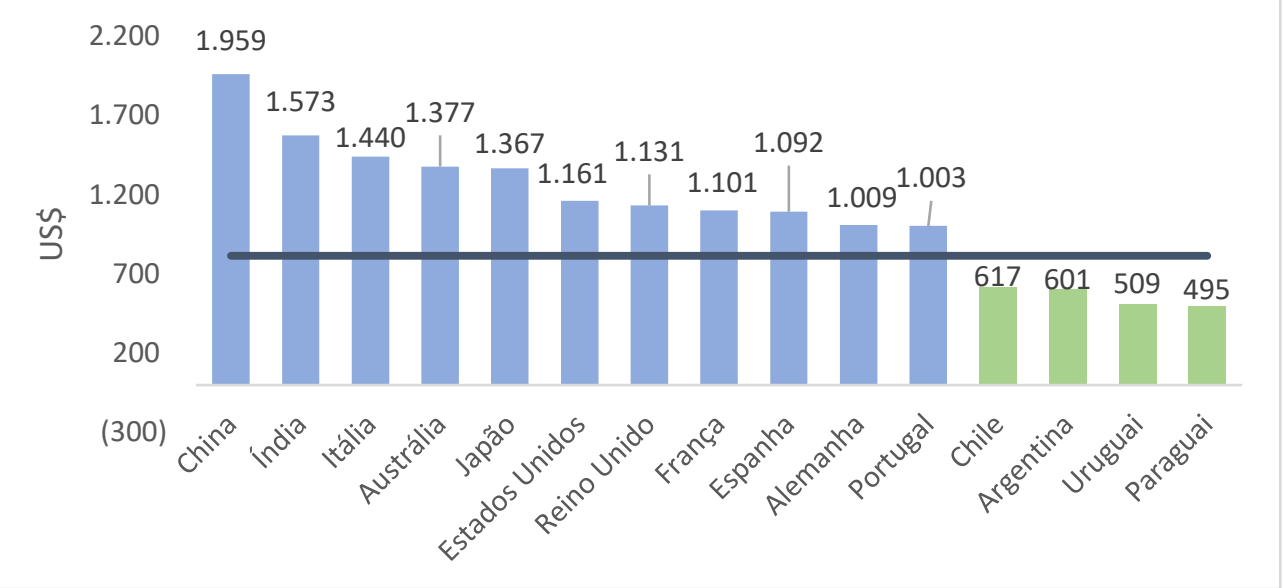

Fonte: Ministério do Turismo - Demanda Turística Internacional - 2018. 
A tese implícita nesta análise é a de que as viagens intracontinentais, mais próximas, são as mais importantes em número de visitantes, mas são as que registram menores gastos per capita e também são as mais sensíveis às variações de câmbio e preços relativos. Por outro lado, as viagens intercontinentais, mais distantes, são menos sensíveis às variações conjunturais e implicam em maiores tempos de permanência e de gastos per capita. Para esse mercado, as ações requeridas no estímulo à atração de turistas e de receitas são mais complexas, por serem, estes emissores, menos sensiveis às variáveis sob controle do destino Brasil, não respondendo, com significância estatística, às variações de câmbio e preços (Rabahy, 2003).

Os gastos turísticos dos principais países do mundo seguem um padrão histórico, com taxas de crescimento quase constantes, passível de variações em seu entorno, em função de crises econômicas mundiais ou por razões das próprias economias emissoras. As participações do Brasil no receptivo mundial e como destino dos principais países emissores do mundo tem magnitude ínfima, variando de 0,04\% no caso da China até $0,84 \%$ para a Itália e com uma média mundial de 0,41\% - Tabela 2. Devido a esta participação marginal, os resultados do turismo com destino ao Brasil não representam grandes movimentos da massa de visitantes destes países.

Tabela 2 - Participação do Brasil como destino dos principais mercados do turismo mundial

\begin{tabular}{lrrc}
\hline Países Emissores & $\begin{array}{r}\text { GASTOS (em US\$ milhões) } \\
\text { Total }\end{array}$ & no Brasil & $\begin{array}{c}\text { Participação do Brasil } \\
\text { na Origem }\end{array}$ \\
\hline China & $277.300,00$ & 110,00 & $0,04 \%$ \\
Estados Unidos & $144.200,00$ & 625,00 & $0,43 \%$ \\
Alemanha & $94.200,00$ & 211,00 & $0,22 \%$ \\
Reino Unido & $75.800,00$ & 175,00 & $0,23 \%$ \\
França & $47.900,00$ & 262,00 & $0,55 \%$ \\
Austrália & $36.800,00$ & 58,00 & $0,16 \%$ \\
Rússia & $34.500,00$ & 23,00 & $0,07 \%$ \\
Canadá & $33.300,00$ & 72,00 & $0,22 \%$ \\
Coréia & $32.000,00$ & 25,00 & $0,08 \%$ \\
Italia & $30.100,00$ & 254,00 & $0,84 \%$ \\
Sub-Total & $806.100,00$ & $1.818,00$ & $0,23 \%$ \\
Demais países & $641.900,00$ & $4.099,20$ & $0,64 \%$ \\
TOTAL & $1.448 .000,00$ & $5.917,20$ & $0,41 \%$ \\
\hline
\end{tabular}

Fonte: UNWTO Barometer - 2019, Ministério do Turismo - Demanda Turística Internacional - 2018 e Banco Central do Brasil - Balanço de Pagamentos 2018.

No entanto, as perspectivas de conquistas marginais deste contingente de visitantes, no médio e longo prazos, são bastante favoráveis ao Brasil, que apresenta enormes potencialidades, características distintas e diferenciadas, dependentes de priorização e de ações agressivas de comercialização e promoção, capazes de produzir um deslocamento para cima no patamar de seu receptivo.

No que tange às despesas, as variações cambiais são mais determinantes e acarretam significativos impactos no saldo da conta de viagens internacionais do balanço de pagamentos no Brasil. A taxa de câmbio afeta, com diferentes intensidades, o lado das receitas (gasto de estrangeiros no Brasil) e o das despesas (gastos dos brasileiros no exterior).

Do lado das receitas, já se demonstrou que apenas os países limítrofes respondem às variações do câmbio e dos preços relativos (Rabahy, 2003). Eles também são muitos afetados por suas próprias condições econômicas. Mesmo não se destacando dentre os principais emissores mundiais, pela razão da predominância dos fluxos inter-regionais, os principais emissores para o Brasil são países da América do Sul. Dentre os 5 primeiros países, 4 deles são da América do Sul e respondem por quase 55\% do total (Argentina, Chile, Paraguai e Uruguai) apenas os Estados Unidos aparecem em $2^{\circ}$ Iugar - Tabela 3.

Caso se pretenda acelerar o crescimento das receitas, dadas as atuais restrições das economias dos países limítrofes, fazem-se necessárias priorizar esta atividade e promover ações que ultrapassem o uso dos instrumentos convencionais, com ações mais agressivas e adequadamente programadas para cada tipo de mercado, particularmente no mercado intercontinental. 
Tabela 3 - Principais Países Emissores de Turistas ao Brasil - 2005 - 2018

\begin{tabular}{|c|c|c|c|c|c|c|c|c|c|c|}
\hline \multicolumn{11}{|l|}{ País de } \\
\hline Residência & 2005 & 2010 & 2011 & 2012 & 2013 & 2014 & 2015 & 2016 & 2017 & 2018 \\
\hline Argentina & 992.299 & 1.399 .592 & 1.593 .775 & 1.671 .604 & 1.711 .491 & 1.743 .930 & 2.079 .823 & 2.294 .900 & 2.622 .327 & 2.498 .483 \\
\hline Estados Unidos & 793.559 & 641.377 & 594.947 & 586.463 & 592.827 & 656.801 & 575.796 & 570.350 & 475.232 & 538.532 \\
\hline Chile & 169.953 & 200.724 & 217.200 & 250.586 & 268.203 & 336.950 & 306.331 & 311.813 & 342.143 & 387.470 \\
\hline Paraguai & 249.030 & 194.340 & 192.730 & 246.401 & 268.932 & 293.841 & 301.831 & 316.714 & 336.646 & 356.897 \\
\hline Uruguai & 341.647 & 228.545 & 261.204 & 253.864 & 262.512 & 223.508 & 267.321 & 284.113 & 328.098 & 348.336 \\
\hline França & 263.829 & 199.719 & 207.890 & 218.626 & 224.078 & 282.375 & 261.075 & 263.774 & 254.153 & 238.345 \\
\hline Itália & 303.878 & 245.491 & 229.484 & 230.114 & 233.243 & 228.734 & 202.015 & 181.493 & 171.654 & 175.763 \\
\hline Reino Unido & 169.514 & 167.355 & 149.564 & 155.548 & 169.732 & 217.003 & 189.269 & 202.671 & 185.858 & 154.586 \\
\hline Espanha & 172.979 & 179.340 & 190.392 & 180.406 & 169.751 & 166.759 & 151.029 & 147.846 & 137.202 & 147.159 \\
\hline Portugal & 357.640 & 189.065 & 183.728 & 168.649 & 168.250 & 170.066 & 162.305 & 149.968 & 144.095 & 145.816 \\
\hline Colômbia & 47.230 & 85.567 & 91.345 & 100.324 & 116.461 & 158.886 & 118.866 & 135.192 & 140.363 & 131.596 \\
\hline Bolívia & 68.670 & 99.359 & 85.429 & 112.639 & 95.028 & 95.300 & 108.149 & 138.106 & 126.781 & 126.253 \\
\hline Peru & 60.251 & 81.020 & 86.795 & 91.996 & 98.602 & 117.230 & 113.078 & 114.276 & 115.320 & 121.326 \\
\hline Demais Países & 985.975 & 955.639 & 1.042 .681 & 1.089 .528 & 1.120 .989 & 1.363 .334 & 1.154 .040 & 1.119 .358 & 924.075 & 961.884 \\
\hline TOTAL & 5.358 .170 & 5.161.379 & 5.433 .354 & 5.676 .843 & 5.813 .342 & 6.429 .852 & 6.305 .838 & 6.546 .696 & 6.588 .770 & 6.621 .376 \\
\hline
\end{tabular}

Fonte: Ministério do Turismo - Anuários Estatísticos - 2006 a 2019.

\subsection{Relações gastos versus câmbio, renda e preços}

Do lado das despesas dos brasileiros com viagens internacionais, dada a demanda reprimida por viagens internacionais de grandes parcelas da população brasileira, o crescimento da renda, a valorização do real e as facilidades de crédito permitiram um expressivo aumento dos gastos dos brasileiros no exterior. A resposta a um desses fatores causais fica evidente no Gráfico 5, em que as variáveis cambio e gastos, transformadas em números índices, se apresentam de forma negativamente correlacionadas.

A relação câmbio x despesas é quase o reflexo de um "espelho": o Real se valoriza, as despesas com viagens (e importações) crescem e o inverso quando o Real se desvaloriza. É notória a expressiva redução dos gastos com viagens internacionais a partir da política de flexibilização cambial (1999): a moeda brasileira se desvaloriza, - passa de 1,0 R $\$ /$ US $\$$ para 2,3 a 3,1 R $\$ / U S \$$ (e para até 4,0 R $\$ / U S \$$ em 2003). Por conta da redução das despesas, a conta viagens internacionais chega a registrar até saldos positivos (2003 e 2004). Em 2005 e 2006 acelera-se a valorização do Real, estimulando o aumento dos gastos com viagens ao exterior.

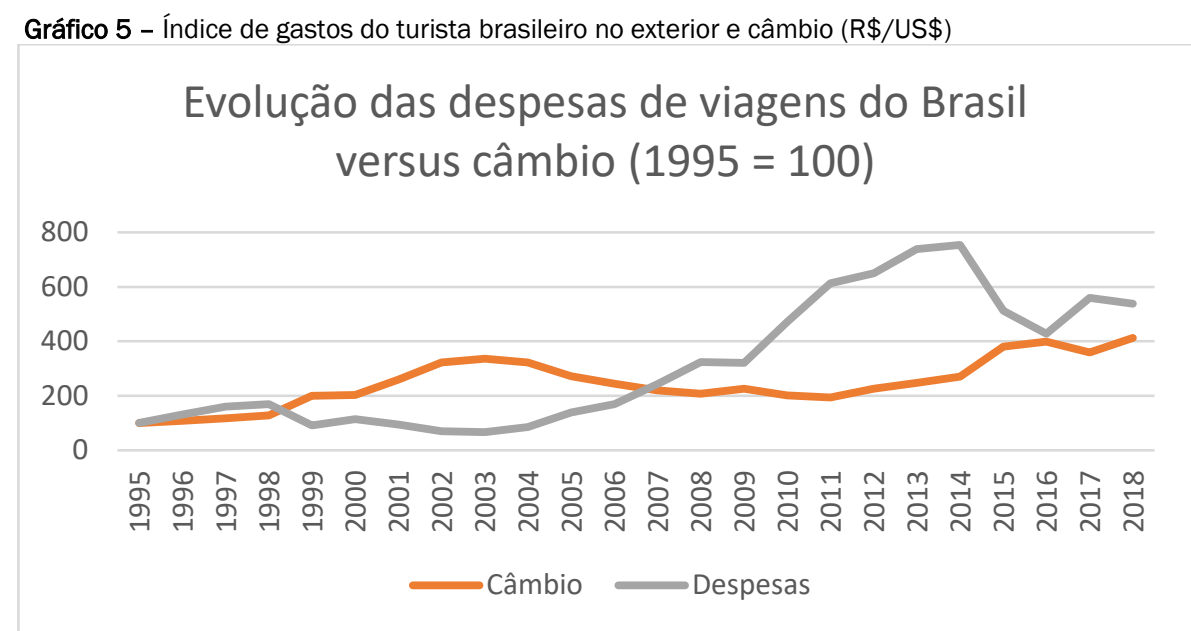

Fonte: Banco Central do Brasil - Balanço de Pagamento BPM6 e Ipeadata.

Certamente outros fatores que não somente o câmbio contribuíram para o crescimento dos gastos com o turismo: o aumento da renda, sua melhor distribuição, a redução dos custos dos produtos turísticos, facilidades de crédito, entre outros. 


\subsection{A Conta Viagens Internacionais do Brasil}

Quanto ao saldo da conta de viagens internacionais, alguns períodos se destacam. Num primeiro momento com o Real valorizado, particularmente nos anos de 1997 e 1998, o déficit desta conta chegou a quase US\$ 4,4 bilhões, por conta da aceleração das despesas. Com a política de flexibilização cambial em 1999, verifica-se uma desvalorização da moeda brasileira, especialmente no período 2001 a 2005, cotação média anual variando entre 2,4 a 3,1 R $\$$ /US $\$$. Neste período os gastos com viagens ao exterior registram expressivas quedas, passando de US $\$ 5,5$ bilhões em 1997/1998, para US $\$ 2,2$ a 2,4 bilhões em $2002 / 2003$, chegando inclusive a produzir saldos positivos na conta de viagens internacionais, nos anos de 2003 e 2004 (Tabela 4).

Com a seguinte tendência de valorização do Real frente ao dólar iniciada a partir de 2005, nota-se uma crescente evolução das despesas com viagens internacionais. De fato, desde 2005, os gastos com viagens internacionais evoluem de um patamar inferior a US\$ 5 bilhões para US $\$ 10$ bilhões em 2008 e 2009, alcançando mais de US\$20 bilhões em 2011 e mais de US\$25 bilhões em 2013 e 2014, chegando a ocasionar déficit de US $\$ 18,7$ bilhões. Mais recentemente, com o Real no patamar de R\$3,3 a 3,8 e a crise interna brasileira (queda da renda dos brasileiros), os gastos com viagens tiveram ligeira redução ao nível de US $\$ 15$ a 18 bilhões. Como visto, a aceleração das despesas, não acompanhada das receitas, chegou a gerar déficits crescentes, até alcançar cerca de quase U\$\$19 bilhões em 2014, hoje em cerca de US\$12 bilhões.

As pesquisas de demanda internacional do Ministério do Turismo realizadas pela FIPE revelam que, além do maior contingente de brasileiros que foram se agregando ao mercado de consumo do turismo internacional, os gastos médios dos turistas também foram se elevando. Conforme resultados descritos na Tabela 5, o gasto médio a preços correntes (em US\$) cresceu 47\%, entre 2005 e 2012, correspondente a uma taxa anual média de $5,7 \%$ a.a. Somente em 2008 e 2009 , como efeito da crise internacional, verificam-se quedas nos gastos médios de, respectivamente, $-9,2 \%$ e $-6,4 \%$. A partir de 2012 , regridem os gastos do nível de $47 \%$ de alta para 14\%, em 2018 em relação a 2005.

Analisando-se estes resultados, verifica-se a relação entre as variações dos gastos médios com as da cotação e valorização do Real: à medida que o Real se valoriza, maiores são os gastos médios. A par da questão do câmbio, tem o problema da redução da renda dos brasileiros, com a crise iniciada em 2015.

\begin{tabular}{|c|c|c|c|c|}
\hline \multirow[b]{2}{*}{ Ano } & Câmbio (turismo) & \multicolumn{3}{|c|}{ Conta Viagens Internacionais (US\$ milhões) } \\
\hline & $\mathrm{R} \$ / \mathrm{US} \$$ & Receitas & Despesas & Saldo \\
\hline 1995 & 0,93 & 971,60 & $3.391,30$ & $-2.419,70$ \\
\hline 1996 & 1,00 & 839,82 & $4.438,27$ & $-3.598,45$ \\
\hline 1997 & 1,09 & $1.068,96$ & $5.445,81$ & $-4.376,86$ \\
\hline 1998 & 1,19 & $1.585,65$ & $5.731,71$ & $-4.146,06$ \\
\hline 1999 & 1,85 & $1.628,18$ & $3.085,29$ & $-1.457,11$ \\
\hline 2000 & 1,88 & $1.809,85$ & $3.894,06$ & $-2.084,21$ \\
\hline 2001 & 2,40 & $1.730,59$ & $3.198,62$ & $-1.468,03$ \\
\hline 2002 & 2,98 & $1.997,97$ & $2.395,80$ & $-397,84$ \\
\hline 2003 & 3,12 & $2.478,67$ & $2.261,09$ & 217,58 \\
\hline 2004 & 2,99 & $3.222,05$ & $2.871,28$ & 350,78 \\
\hline 2005 & 2,52 & $3.861,44$ & $4.719,86$ & $-858,42$ \\
\hline 2006 & 2,26 & $4.315,89$ & $5.763,72$ & $-1.447,84$ \\
\hline 2007 & 2,04 & $4.952,97$ & $8.211,18$ & $-3.258,22$ \\
\hline 2008 & 1,93 & $5.785,03$ & $10.962,36$ & $-5.177,33$ \\
\hline 2009 & 2,09 & $5.304,56$ & $10.898,16$ & $-5.593,60$ \\
\hline 2010 & 1,87 & $5.261,03$ & $15.965,38$ & $-10.704,35$ \\
\hline 2011 & 1,79 & $6.094,69$ & $20.801,82$ & $-14.707,13$ \\
\hline 2012 & 2,09 & $6.378,06$ & $22.038,72$ & $-15.660,66$ \\
\hline 2013 & 2,29 & $6.473,99$ & $25.028,31$ & $-18.554,33$ \\
\hline 2014 & 2,50 & $6.842,63$ & $25.566,80$ & $-18.724,17$ \\
\hline
\end{tabular}


Tabela 4 - Resultados da Conta Viagens Internacionais versus Câmbio

(conclusão)

\begin{tabular}{lrrrr}
\hline & Câmbio (turismo) & \multicolumn{2}{c}{ Conta Viagens Internacionais (US\$ milhões) } \\
Ano & R $\$ /$ US\$ & Receitas & Despesas & Saldo \\
\hline 2015 & 3,53 & $5.843,95$ & $17.356,83$ & $-11.512,87$ \\
2016 & 3,70 & $6.023,80$ & $14.496,91$ & $-8.473,11$ \\
2017 & 3,32 & $5.809,21$ & $19.001,63$ & $-13.192,42$ \\
2018 & 3,82 & $5.920,64$ & $18.265,50$ & $-12.344,87$ \\
\hline
\end{tabular}

Fonte: Banco Central do Brasil - Balanço de Pagamento BPM6 e Ipeadata.

Feitas estas colocações é essencial que se examine como se compõem estes gastos dos viajantes brasileiros, para que se entenda outras razões do seu crescimento. Nota-se na Tabela 6 que os gastos médios com hospedagem e alimentação, embora tenham aumentado ligeiramente no período, claramente deixaram de ser os principais responsáveis do gasto total. Dentre os outros itens de gastos tipicamente associados com o turismo, verifica-se que apenas o gasto médio com transportes nos locais de destinos apresentou de fato um aumento significativo, isto até 2011, retornando ao patamar inicial depois. De outro lado, visita a atrativos registra significativos recuos no início, mantendo-se depois.

Tabela 5 - Gasto médio dos turistas brasileiros no exterior e câmbio

\begin{tabular}{|c|c|c|c|c|}
\hline & Câmbio (turismo) & Gasto per capita médio & Índice dos Gastos & Variação Anual dos \\
\hline Ano & $\mathrm{R} \$ / \mathrm{US} \$$ & no exterior & $(2005=100)$ & Gastos (\%) \\
\hline 2005 & 2,52 & $1.139,19$ & 100,0 & - \\
\hline 2006 & 2,26 & $1.158,89$ & 101,7 & 1,7 \\
\hline 2007 & 2,04 & $1.601,85$ & 140,6 & 38,2 \\
\hline 2008 & 1,93 & $1.454,75$ & 127,7 & $-9,2$ \\
\hline 2009 & 2,09 & $1.361,96$ & 119,6 & $-6,4$ \\
\hline 2010 & 1,87 & $1.515,56$ & 133,0 & 11,3 \\
\hline 2011 & 1,79 & $1.638,90$ & 143,9 & 8,1 \\
\hline 2012 & 2,09 & $1.677,16$ & 147,2 & 2,3 \\
\hline 2013 & 2,29 & $1.611,11$ & 141,4 & $-3,9$ \\
\hline 2014 & 2,50 & $1.646,53$ & 144,5 & 2,2 \\
\hline 2015 & 3,53 & $1.375,22$ & 120,7 & $-16,5$ \\
\hline 2016 & 3,70 & $1.281,00$ & 112,4 & $-6,9$ \\
\hline 2017 & 3,32 & $1.402,51$ & 123,1 & 9,5 \\
\hline 2018 & 3,82 & $1.294,58$ & 113,6 & $-7,7$ \\
\hline
\end{tabular}

Fonte: Ministério do Turismo - FIPE - Pesquisa de Demanda Internacional - 2005 a 2018.

O item que chama a atenção quanto ao crescimento do gasto, e é o que efetivamente mais contribuiu para o aumento do gasto médio total, foi o das compras pessoais, o qual inclusive passou a ser, na média, o principal item de despesa dos brasileiros em viagem no exterior a partir de 2009 até 2015.

\begin{tabular}{lrrrrrrrrrrrrr}
\multicolumn{10}{l}{ Tabela 6 - Composição dos gastos de brasileiros no exterior - 2006 - 2018 (em \%) } \\
\hline Itens de gastos & $\mathbf{2 0 0 6}$ & $\mathbf{2 0 0 7}$ & $\mathbf{2 0 0 8}$ & $\mathbf{2 0 0 9}$ & $\mathbf{2 0 1 0}$ & $\mathbf{2 0 1 1}$ & $\mathbf{2 0 1 2}$ & $\mathbf{2 0 1 3}$ & $\mathbf{2 0 1 4}$ & $\mathbf{2 0 1 5}$ & $\mathbf{2 0 1 6}$ & $\mathbf{2 0 1 7}$ & $\mathbf{2 0 1 8}$ \\
\hline Hospedagem & 25,3 & 29,8 & 25,4 & 22,4 & 21,6 & 22,1 & 24,4 & 23,8 & 23,8 & 25,5 & 28,9 & 27,0 & 27,7 \\
Alimentação & 26,3 & 26,0 & 24,8 & 24,2 & 24,9 & 23,4 & 24,3 & 23,6 & 23,9 & 26,0 & 26,5 & 27,0 & 27,1 \\
Transportes & 10,5 & 10,0 & 15,5 & 15,4 & 14,5 & 13,5 & 9,6 & 10,0 & 9,7 & 8,9 & 10,0 & 10,1 & 10,4 \\
Compras Pessoais & 17,6 & 16,7 & 23,9 & 27,7 & 28,2 & 30,5 & 30,7 & 29,8 & 28,6 & 26,8 & 22,3 & 23,2 & 21,4 \\
Visita a Atrativos & 17,7 & 16,2 & 9,3 & 9,1 & 9,4 & 9,2 & 10,0 & 11,4 & 10,3 & 10,8 & 9,6 & 10,5 & 10,0 \\
Outras Despesas & 2,7 & 1,2 & 1,1 & 1,3 & 1,3 & 1,4 & 1,1 & 1,3 & 3,8 & 2,0 & 2,7 & 2,2 & 3,2 \\
Total & 100,0 & 100,0 & 100,0 & 100,0 & 100,0 & 100,0 & 100,0 & 100,0 & 100,0 & 100,0 & 100,0 & 100,0 & 100,0
\end{tabular}

Fonte: Ministério do Turismo - FIPE - Pesquisa de Demanda Internacional - 2005 a 2018.

Embora as compras naturalmente façam parte das atividades envolvidas nas viagens de turismo, nos níveis que as mesmas atingiram, superando inclusive os gastos com alimentação ou com hospedagem, dificilmente podem ser consideradas na sua totalidade como gastos devidos ao turismo. Há algum tempo vem se observando que a valorização do Real tem estimulado a substituição da compra de produtos nacionais por importados, estímulo esse que evidentemente se dá com maior ênfase nos brasileiros em 
viagem ao exterior. Inclusive, tornou-se até corriqueiro no período recente, a ocorrência de viagens ao exterior apenas para a realização de compras.

Assim, embora seja esperado que a valorização da moeda brasileira estimule o turismo internacional de brasileiros, o que merece ser ressalvado é a afirmação de que nem todo o montante de gastos no exterior, da conta viagens internacionais, seja devido a gastos de turismo. De fato, uma parcela nada desprezível das saídas de divisas deve ser relacionada muito mais com a importação de bens, do que propriamente com gasto de turismo, uma vez que, pelos atuais critérios do Banco Central do Brasil, as compras do exterior com cartão de crédito, mesmo quando não realizadas no destino, são registradas como despesas de viagem de turismo. Ou seja, até mesmo uma compra realizada por um consumidor, no Brasil, com o uso da internet em sites estrangeiros, é contabilizada como despesa de viagens internacionais nas contas do Banco Central do Brasil.

Quanto ao fluxo de turistas estrangeiros para o Brasil, a situação é pouco favorável, com reduzidos avanços positivos ao longo do tempo. Em 2018 o país recebeu 6,6 milhões de turistas, enquanto 19 anos antes (em 2000) já havia alcançado 5,3 milhões. A participação do Brasil no mercado em número de chegadas internacionais, por sua vez, caiu de 0,8\%, em 2000, para 0,47\% em 2018.

\section{PERSPECTIVAS DO TURISMO NO BRASIL}

\subsection{Turismo Doméstico: Base de Sustentação do Turismo no Brasil}

Embora o significado do turismo numa dada economia muitas vezes seja representado pela relevância do turismo internacional, o que se verifica na maioria dos países é que a base para o crescimento do turismo tem sido propiciada pela formação e desenvolvimento do mercado interno. Mesmo em alguns casos em que o mercado externo se revela o mais importante, o mercado interno, em valores absolutos, pode representar alto significado no contexto total. A Tabela 6, inspirada em Bull (1994), estabelece a relação entre a participação do turismo doméstico e internacional em alguns dos principais países do turismo mundial.

Dentre os 13 países constantes dessa tabela, em apenas dois - Áustria e Espanha -, o mercado interno não supera o internacional, nos demais o doméstico é sempre superior, alcançando na China e Japão valores de 9,5 e 14,4 vezes. Convém destacar que no Brasil a principal força motora do turismo é dada pelo mercado interno, cujo consumo turístico representa 9,9 vezes mais do que o consumo turístico de estrangeiros no Brasil.

Tabela 7 - Turismo doméstico versus internacional

\begin{tabular}{|c|c|c|c|c|}
\hline \multirow[b]{2}{*}{ País } & \multirow{2}{*}{$\begin{array}{r}\text { Ano de } \\
\text { Referência }\end{array}$} & \multicolumn{2}{|c|}{ Receitas do Turismo (US $\$$ bilhões) } & \multirow{2}{*}{ Relação D/I } \\
\hline & & Internacional (I) & Doméstico (D) & \\
\hline Estados Unidos & 2006 & 84 & 593,7 & 7,1 \\
\hline França & 2005 & 54 & 126,6 & 2,3 \\
\hline Espanha & 2004 & 49,3 & 48,7 & 1,0 \\
\hline Áustria & 2005 & 17,9 & 17 & 0,9 \\
\hline México & 2006 & 15,3 & 96,2 & 6,3 \\
\hline Japão & 2007 & 12,6 & 181 & 14,4 \\
\hline Austrália & 2003 & 11,5 & 32,4 & 2,8 \\
\hline Canadá & 2002 & 11,5 & 24,5 & 2,1 \\
\hline Suíça & 2005 & 9,6 & 14,8 & 1,5 \\
\hline Holanda & 2007 & 9,3 & 39,1 & 4,2 \\
\hline China & 2002 & 1,1 & 10,4 & 9,5 \\
\hline Chile & 2003 & 1,1 & 3,8 & 3,5 \\
\hline Brasil & 1999 & 3,9 & 38,8 & 9,9 \\
\hline
\end{tabular}

Fonte: UNTWO - TSA data around the world, 2009 e Embratur, FIPE - Impacto Econômico do Turismo Avaliado pela Conta Satélite, 2002. 


\subsection{Oportunidades no Receptivo mundial}

Uma nova perspectiva de diversificação de destinos decorre, além dos fatores de renda e de tempo disponiveis, de um processo de saturação dos mercados tradicionais, com progressivo transbordamento de suas fronteiras, em direção a novos destinos e, na margem, para localidades mais distantes, em busca de atrativos únicos e/ou exóticos, característicos de segmentos pioneiros de viajantes, que depois se propagam a outros tipos de consumidores.

Nesse contexto, tem-se espaço para no médio e longo prazos competir pela absorção da natural redistribuição do fluxo turístico às novas destinações, mesmo que em escalas apenas marginais.

Considerando a grande concentração das viagens na própria região de origem, a localização do país em relação aos principais países emissores de turistas constitui-se em significativo fator determinante no crescimento do receptivo. Em 2018 a receita do turismo mundial atingiu US\$1.448 bilhões. Deste total o Brasil, com receita de US $\$ 5,92$ bilhões, responde por somente $0,41 \%$ do total. 0 Brasil compõe o grupo de destinos mais distantes dos principais emissores. Esse tipo de destino não é próprio de um público de massa, mas de pioneiros, mais sofisticados, que, gradualmente, vem ampliando sua participação, embora, em números ainda não expressivos e que ainda não vêm priorizando os destinos brasileiros.

Nesse cenário, as possibilidades de crescimento do turismo internacional no Brasil dependem principalmente do desempenho econômico de seus países fronteiriços, inclusive em termos de taxa de câmbio, renda e preços, e da valorização de atrativos únicos de que dispomos, por meio da melhoria da infraestrutura, dos serviços de apoio ao turismo e da intensificação e maior agressividade nos procedimentos de comercialização e de promoção do turismo brasileiro, ações estas sustentadas pelo fortalecimento do turismo doméstico.

A situação atual ainda não representa todo o potencial do Brasil no receptivo mundial. Como apresentados nos dados da Tabela 2, dentre os principais países emissores do turismo mundial, exceção à Itália $(0,84 \%)$ e França ( $0,55 \%)$, todos os demais destinam menos de $0,5 \%$ de seus gastos ao Brasil.

\subsection{Impactos do Turismo na Distribuição de Renda}

O turismo pode ser considerado uma importante atividade econômica, capaz de impulsionar o crescimento de algumas regiões que apresentem condições para a sua propagação. Entre os benefícios que podem ser gerados por esta atividade destacam-se os de contribuir para a redução das desigualdades regionais e pessoais de renda, para a geração de divisas e para a criação de empregos. Neste aspecto em particular, por se constituir preponderantemente numa atividade do setor serviços, que notadamente utiliza mão-deobra de forma intensiva, o potencial gerador de empregos do turismo é muito relevante, sendo, também por isso, a base do crescimento da economia de regiões ou mesmo países.

Como pode ser verificado nos dados exibidos na Tabela 7, o turismo exerce importante papel de redistribuição regional da renda. De fato, observa-se que para cada 1 Real de gasto do Nordeste no Sudeste, o Sudeste desembolsa 3 reais unidades monetárias no Nordeste.

Tabela 8 - Fluxos de gastos e receitas turísticas em viagens domésticas no Brasil (em \%)

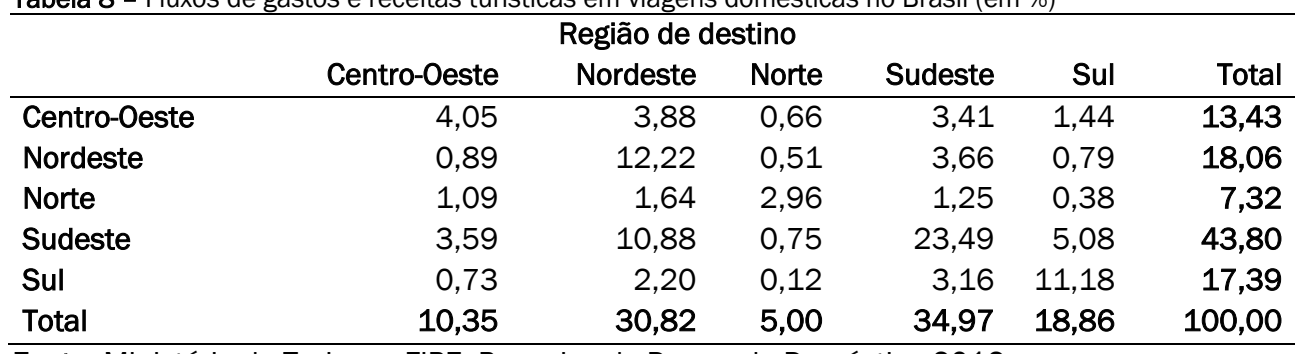

Fonte: Ministério do Turismo, FIPE. Pesquisa de Demanda Doméstica 2012.

De outro lado, nota-se a importância relativa deste setor de atividade para as regiões menos desenvolvidas. $\mathrm{Na}$ Tabela 8 verifica-se que, embora o Sudeste seja a região que mais arrecada com o turismo em valores 
absolutos (35\% do total), em termos relativos de seus respectivos produtos internos brutos representa $1,88 \%$, contra $6,84 \%$ do Nordeste, revelando ser um setor especial para esta região. Assim, notoriamente, o turismo propicia redistribuição regional da renda.

\begin{tabular}{lrrrrrr}
\multicolumn{2}{l}{ Tabela 9 - Significado relativo do turismo no PIB, por região do Brasil } \\
\hline & Centro-Oeste & Nordeste & Norte & Sudeste & Sul & Brasil \\
\hline Impacto Direto Turismo & 12.455 & 39.913 & 6.578 & 46.145 & 25.245 & 130.337 \\
PIB (2011) & 400.153 & 583.413 & 241.028 & 2.455 .542 & 696.247 & 4.376 .382 \\
Turismo / PIB (\%) & 3,11 & 6,84 & 2,73 & 1,88 & 3,63 & 2,98 \\
\hline
\end{tabular}

Fonte: Ministério do Turismo, FIPE. Pesquisa de Demanda Doméstica 2012 e IBGE.

\section{ALGUMAS RECOMENDAÇÕES PARA O TURISMO NO BRASIL}

Há muito tempo a aceleração do crescimento do turismo no Brasil constitui-se em permanente desafio para sua consecução. As recomendações aqui contidas reforçam algumas já conhecidas, ao lado de outras que emergem especificamente da análise realizada e de outras considerações.

O Brasil deve basear o crescimento de seu turismo a partir do fortalecimento do mercado interno que, além de seus benefícios, gera externalidades para a sustentação do crescimento do turismo internacional.

Este deve ocorrer articulado com todas as instâncias deste setor de atividade, atentando para dois aspectos principais. 0 primeiro se refere à priorização dos segmentos de mercado mais típicos para uma dada região, tanto no que tange à sua procedência, de origem doméstica ou do exterior, quanto no que tange ao segmento que representa, em termos de níveis de renda, motivações de viagens e perfil psicográfico, entre outros.

O outro diz respeito à estratégia a ser adotada numa dada região para promover-se o crescimento das atividades do turismo: ordenar e facilitar a tendência espontânea manifestada, a partir das forças da demanda, ou, alternativa e complementarmente, enfatizando-se o lado da oferta, orientando-se e estimulando novos investimentos públicos e privados na região.

Atenção especial deve ser dada à questão da sazonalidade das viagens, mediante iniciativas para aliviá-la, de modo a assegurar uma escala mínima ao longo do ano para diluir seus custos fixos e, por conseguinte, reduzir seus custos unitários. Há várias iniciativas nessa direção: uma delas é a de ampliar programas específicos para a população da melhor idade. Tem-se, no Brasil, uma clara tendência de envelhecimento da população, com o contingente de idosos aumentando significativamente a cada ano.

Parcela expressiva desse contingente é aposentada e não tem restrições ligadas ao trabalho que inviabilizam o exercício de atividades do turismo fora dos períodos de férias. Nessa linha, caberia planejar também a possibilidade de que algumas localidades turísticas fossem equipadas com serviços de atendimentos especiais para este público, particularmente na época fora da alta estação.

Finalmente, deve-se buscar uma maior integração com outros setores, particularmente com o meio ambiente e esportes. E no caso específico do Turismo receptivo internacional, uma das ações que se recomenda é a instalação de postos avançados de comercialização no exterior, junto aos principais aeroportos internacionais, integrando os setores públicos e privados, neste caso especialmente as companhias aéreas e agências de viagens, e, no setor público as agências dos setores referidos, conjuntamente com os órgãos dos Estados.

Não se afigura como adequado que haja distanciamento dos órgãos que de alguma forma interagem com essas questões do turismo. A atuação mais conjugada, além da sinergia que propicia, resultará na ascensão dessas atividades na escala de prioridades do governo.

\section{REFERÊNCIAS}

Banco Central do Brasil (2019). Balanço de Pagamentos - BPM6. Disponível em: https://www.bcb.gov.br/estatisticas/tabelasespeciais. Acesso em: 19/07/2019.

Brasil. Ministério do Turismo (2019). Anuário Estatístico de Turismo - 2019. 46, ano base 2018. Brasília: Ministério do Turismo. 
Bull, A. (1994). La Economía del Sector Turístico. Alianza Editorial, Madrid.

EMBRATUR. (2002). Conta Satélite do Turismo: Brasil: 1999. Brasília: EMBRATUR.

Haddad, E. A.; Porsee, A. A. \& Rabahy, W. A. (2013). Domestic tourism and regional inequality in Brazil. Tourism Economics, 19(1), 173-186. https://doi.org/10.5367\%2Fte.2013.0185

IBGE. (2012). Economia do Turismo: Uma Perspectiva Macroeconômica 2003-2009. Estudos e Pesquisas Informação Econômica, 18. Rio de Janeiro: IBGE.

Kadota, D. K. \& Rabahy, W. A. (2003). Conta Satélite de Turismo no Brasil: método de avaliação do impacto econômico do turismo. Turismo em Análise, São Paulo, 14(1), 65-84. https://doi.org/10.11606/issn.19844867.v14i1p65-84

Rabahy, W. A. (2003). Turismo e Desenvolvimento: Estudos Econômicos e Estatísticos no Planejamento. Barueri (SP): Manole.

Rabahy, W. A.; Silva, J. C. D. \& Vassallo, M. D. (2007). Os Efeitos Assimétricos da Taxa de Câmbio Real sobre a Conta de Viagens Internacionais do Balanço de Pagamentos Brasileiro. Boletim de Informações FIPE. São Paulo: FIPE. https://doi.org/10.11606/issn.1984-4867.v19i2p293-306

UNWTO. (2018). Tourism Highlights. Madrid: UNWTO.

UNWTO. (2019). World Tourism Barometer. Madrid: UNWTO.

\section{Informações dos autores}

\section{Wilson Abrahão Rabahy}

Professor titular aposentado da Escola de Comunicações e Artes da Universidade de São Paulo (ECA-USP). Doutor e livredocente em Ciências da Comunicação. Coordenador de inúmeras pesquisas de turismo realizadas pela Fundação Instituto de Pesquisas Econômicas (FIPE) para entidades como o Ministério do Turismo (MTUR), Agência Nacional de Aviação Civil (ANAC), Banco Interamericano de Desenvolvimento (BID), Banco Nacional de Desenvolvimento Econômico e Social (BNDES), Ministério do Meio Ambiente, Serviço de Apoio às Micro e Pequenas Empresas (SEBRAE), além de vários governos estaduais e municipais. Foi pioneiro e se tornou referência no estudo do turismo pela perspectiva econômica no Brasil.

Sua reputação Ihe rendeu o primeiro prêmio de prêmio entregue pela ANPTUR a um pesquisador. ORCID: https://orcid.org/0000-0001-8842-7073 